
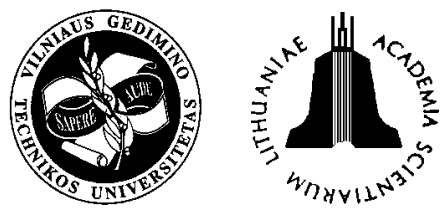

ISSN 1648-4142 print / ISSN 1648-3480 online TRANSPORT

www.transport.vtu.lt

\title{
ELECTRIC DRIVES OF TRACTION ROLLING STOCKS WITH AC MOTORS
}

\author{
Leonas Povilas Lingaitis ${ }^{1}$, Lionginas Liudvinavičius ${ }^{2}$ \\ Dept of Railway Transport, Vilnius Gediminas Technical University, J. Basanavičiaus g. 28, \\ LT-03224 Vilnius, Lithuania.E-mail: ${ }^{1}$ leonasl@ti.vtu.lt; ${ }^{2}$ geltr@ti.vtu.lt \\ Received 1 March 2006; accepted 9 May 2006
}

\begin{abstract}
The paper considers the variation of circuit design of the electric drives in traction rolling stocks when traditional DC electric machines are replaced with AC electric machines. Simplified circuit diagrams of the electric drives using electric machines of non-commutator type are offered. Operational defects of DC traction engines are weighed against some positive characteristics of direct current series excitation in traction engines, determining their extensive use in the electric drives of traction rolling stocks. However, the rapid development of semiconductor devices, e.g. thyristors and IGBT transistors, led to the creation of a great variety of semiconductor inverters. This made it possible to develop an autonomous three-phase power supply system for diesel locomotives and algorithms for the AC traction motors and to obtain engine characteristics matching the tractive force by using voltage frequency and current inverters. A mathematical justification of the engine torque and tractive force control as well as its particular characteristics is provided. The graphs demonstrating the particular ways of changing the electrical parameters of an asynchronous motor with a squirrel-cage rotor are also presented.
\end{abstract}

Keywords: voltage, frequency, power, moment, tractive force, locomotive speed, magnetic field.

\section{Introduction}

In view of the prospect of using electric traction on Lithuanian railways, the problem of proper selection of electric locomotives and electric trains as well as the electric traction machines and their control systems comes to the forefront [1].

Long-term use of diesel locomotives, electric locomotives and electric trains based on DC-DC, AC-AC systems [2] proved unreliability of traction engine as part of the electric drive. Most failures of a DC traction motor are associated with the damages in commutator, brushes and insulation due to mechanical, electric and thermal overload which may be caused by heavy vibration, slipping, cooling air filter clogging, moisture, etc.

It is well-known that maintenance of a commutator machine is very expensive, requiring regular inspection of commutator, brushes and brush holders. The commutator plates wear out due to friction of brushes on the commutator. Besides, brushes should be regularly checked (because the parameters of the springs are changing) and replaced. Commutation effects create an additional reactive electromotive force, impairing overall commutation as well as causing commutator sparking resulting in irreparable defects. Due to these disadvantages, DC traction motors can hardly be considered a promising technology.

However, traditional series-wound traction motors extensively used in diesel locomotives, electric trains, trams, trolleybuses, etc. had some advantages and satisfied the requirements raised to engines at that time. One of the advantages was a great tractive force developed when the train started off. Moreover, in this mode, a torque of the engine in the linear portion of magnetic characteristic is proportional to the square of the armature current value, a drooping speed-torque characteristic completely satisfies the requirements when tractive resistance is changing, and speed and torque control is relatively simple.

However, the rapid development of semiconductor technology led to the creation of powerful energy converters. Famous electrotechnical equipment companies in the world, e.g. SIEMENS, BOMBARDIER TRANSPORTATION, GEC ALSTOM are searching for efficient methods of adjusting AD electric machines to establish a functional relationship between various electric circuit parameters, i.e. supply voltage, amplitude, frequency, torque and tractive force. Currently developed control methods demonstrate the advantages of non-commutator types of electric machines for traction. 


\section{The structure and control system of the electric drives of modern traction rolling stock}

The electric drives of a new AC-AC type can be made according to the diagrams presented in Fig 1.

A simple AC electric drive (Fig 1, a) is made of a synchronous generator SG and some asynchronous traction motors with a squirrel-cage rotor and is 'transparent' in the sense that the shaft torque of the traction motor is proportional to the generator's shaft torque (when the losses are not taken into consideration).

The supply voltage frequency varies mainly because of the variation in the number of camshaft revolutions. If required, the number of the pairs of poles in the generator and traction motors may be changed. The electric drive described here has no inverters to control the voltage. Only the excitation regulators of the synchronous generator GG are used.

An electric drive consisting of a DC generator NSG, inverters and asynchronous traction motors (see Fig 1, b) is referred to as an electric drive of the directalternative current system [3].

The supply voltage frequency of traction motors is varied by inverters independently of the generator shaft revolutions.

Regulators are used in a DC generator excitation circuit, as well as in other models considered. Moreover,

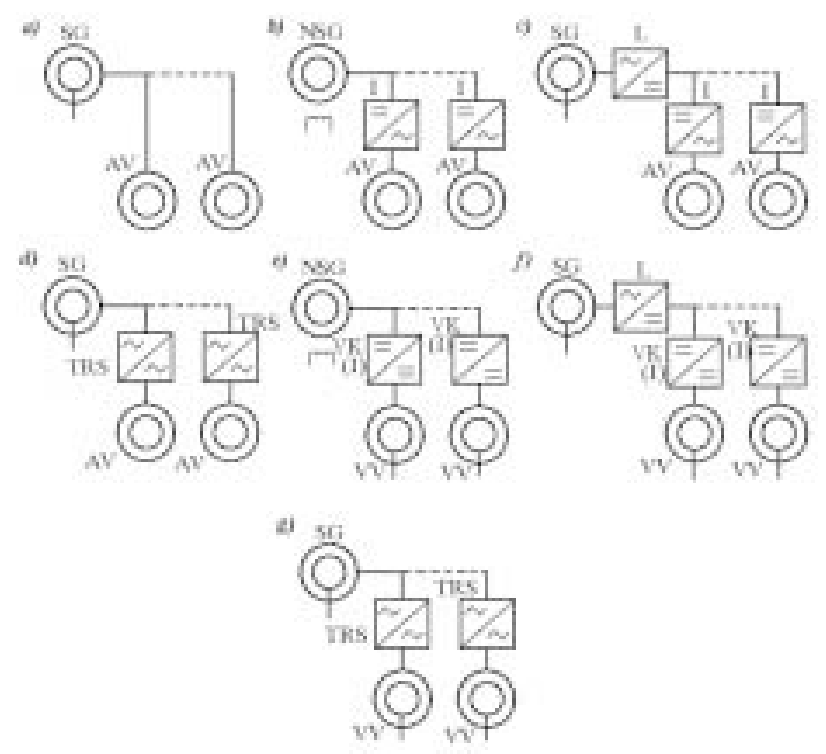

Fig 1. Types of diesel locomotive electric drives used with non-commutator traction motors:

$\mathrm{SG}$ - a synchronous generator; NSG - a DC generator; $\mathrm{AV}$ - denotes asynchronous traction motors;

TRS - a feedforward frequency converter; VV - denotes thyratron motors; VK - is a thyratron commutator; $\mathrm{I}$ - denotes inverters; $\mathrm{L}$ - denotes equalizers individual or group frequency regulators (for individual traction motors or their group, respectively) should be provided. Asynchronous traction motors can be connected to an individual inverter or, in parallel, to a commonly used inverter.

The electric drive (illustrated in Fig 1, c) differs from that described above in the type of generator used in this case, a DC generator has been replaced with a synchronous generator $\mathrm{SG}$ and an equalizer $\mathrm{L}$ which may be either controlled or non-controlled. The latter may also be provided for each inverter individually, though, in most cases, it is a shared device. In the case of a controlled equalizer, its control system is either connected with the control system of generator or inverter or is separated from them. An inverter made of an equalizer and an autonomous inverter is referred to as frequency inverter with a DC intercircuit. This type of electric drive system is known as $A C-D C-A C$ system.

In the electric drive, shown in Fig 1, d, feedforward frequency converters, TRS, with a feedforward input and output circuit are used instead of an intermediate DC circuit. In such systems, voltage is equalized at a frequency depending on generator's parameters, while current is inverted at a frequency determined by the locomotive speed, using the same rectifiers [4].

The control system of the inverters of the above described electric drive is more complicated than that of TRS inverters and is referred to as an $A C-A C$ system.

The structure of the electric drives with thyratron engines (see Fig 1, e, f, g) is similar to the drives with asynchronous motors and inverters.

A system made of a DC generator NSG, a rectifier commutator VK and thyratron engines VV is illustrated in Fig 1, e. The commutator functions can be performed by autonomous inverters similar to asynchronous motor inverters, therefore, they are often referred to as inverters. In addition to regulators similar to those used in drives with asynchronous motors, engine excitation regulators are also used. According to its characteristics, this system is close to a DC drive and may be compared with an AC system because the structure of the engines is similar to that of synchronous motors.

In the electric drive shown in Fig 1, g, frequency inverters TRS of a feed forward system function as equalizer and commutator.

In the present paper several, but not all, available circuit designs of AC electric drives have been considered. Different types of electric drives have been tested in the USA, Germany, Russia, Switzerland, Hungary, etc. 


\section{Alternative current asynchronous traction motors}

From the perspective of modern technological development, asynchronous motors could be considered as most suitable for locomotives. Due to their relatively small mass (without commutator and brushes), asynchronous traction motors with a squirrel-cage rotor can be successfully used in high-speed locomotives.

An asynchronous motor with a squirrel-cage rotor has a relatively small starting torque and heavy starting current. To increase the torque and to decrease the current, it is possible to use a "cage"-type rotor with higher resistance, increasing, however, the slip of the engine and losses of the rotor circuit.

\section{Modes of asynchronous motor operation}

One of the key parameters [5] of asynchronous motors, is relative slip expressed by the formula:

$$
s=\frac{n_{1}-n_{2}}{n_{1}},
$$

where $n_{1}$ - the speed of the rotor's rotating field; $n_{2}$ - the rotational speed of the rotor.

Current frequency of the stator windings (or the magnetic field frequency) $f_{1}=p n_{1} / 60$, while the speed of the rotor's magnetic field is $f_{2}=p n_{2} / 60$ (where $p$ is the number of the pairs of poles). Then:

$$
s=\frac{f_{1}-f_{2}}{f_{1}} .
$$

The difference $f_{1}-f_{2}=\Delta f$ is referred to as absolute rotational speed of the rotor. The frequency of
EMF induced by the rotating rotor is the same.

According to the formula (2), absolute rotor slip frequency $\Delta f$ will be as follows:

$$
\Delta f=s f_{1} \text {. }
$$

When the load is nominal, the rotational speed of the rotor of an asynchronous motor makes 98,0-92,5\% of the speed of the stator's rotating field $n_{1}$ (the assigned slip $s_{\text {vard }}$ is usually about 2-7,5\%). Relative slip $s$ is equal to one (and can reach zero), when a rotor is stopped. The higher the load, i.e. the torque of an electric motor, the lower the rotational speed of the rotor $n_{2}$. As shown by the speed-torque characteristic of asynchronous motors $n=f(M)$ (see Fig 2), the rotational speed of the engine's rotor is only slightly decreased when the load is increased [6]. This motor's characteristic is referred to as flat. The highest electromagnetic torque value is achieved by the engine when the slip is critical, $s_{k r}$, reaching 10-20\%, depending on the engine design. The ratio $M_{\text {max }} / M_{\text {vard }}$ shows the engine's overload and is referred to as loading factor (or admissible current). It is usually equal to $1,8-2,5$. The ratio $M_{p} / M_{\text {vard }}$ shows the engine's overload and is referred to as starting coefficient and determines the starting conditions. It depends on the rotor design in asynchronous motors, being equal to $1-1,9$ for ordinary rotors; 1,7-2,2 for increased slip rotors, and 1,7-1,8 for rotors with an increased starting moment.

The stable performance can be achieved only if an electric motor is self-regulating, i.e. automatically restoring the balance between the counter (load) torque

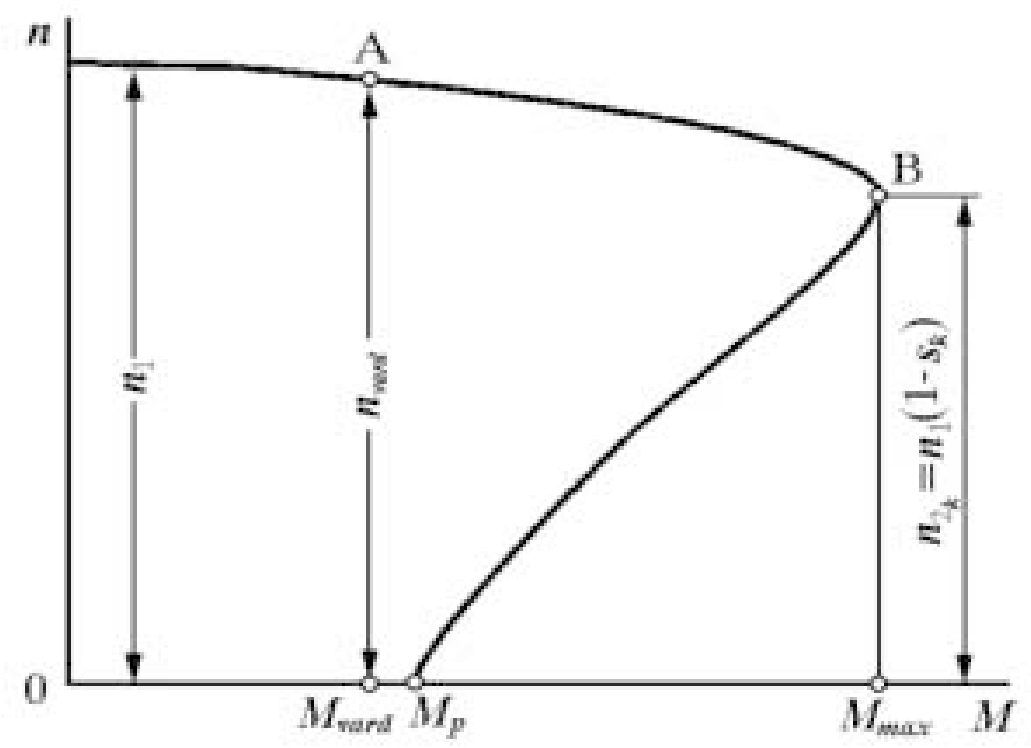

Fig 2. Natural speed-torque characteristic of asynchronous motor $n=f(M): s_{k}$ - critical slip; $n_{2 k}-$ critical rotational speed of rotor; $M_{\text {vard }}-$ nominal (rated) torque of asynchronous motor; $M_{p}$ - starting torque 
and the engine's torque. This condition is met by the upper part of the characteristic up to point $\mathrm{B}$ of $M_{\max }$. If the load torque is higher than the engine torque $M_{\max }$, the engine becomes unstable and stops. At this time, the current running through the machine winding is 5-7 times more than that of the nominal current.

In traction and electric braking modes, relative slip $s$ does not completely characterize asynchronous motor performance. Therefore, when starting a locomotive, its speed should be regulated, i.e. $f_{1}$ and $f_{2}$ should be changed together with the traction motor voltage. Thus, modes of asynchronous traction motor operation may differ for the same relative slip $s$. Taking into account that the maximum engine torque also depends on the stator's supply voltage and current frequency, the stability margin of traction motor torque will vary with the change of the locomotive operation mode.

Since $n_{2}=n_{1}(1-s)=60 f_{1} / p(1-s)$, the revolution of asynchronous motor's rotor $n_{2}$ may be adjusted in the following ways [7]:

1) by adjusting supply voltage frequency $f_{1}$ (frequency regulation), the rotating magnetic field frequency $n_{1}$ can be controlled;

2) by varying the number of pairs of the stator's and rotor's poles, the rotating magnetic field frequency $n_{1}$ can be discretely changed;

3) by adjusting slip $s$ (not using slip energy), the nature of the speed-torque characteristic can be changed. Flat characteristic may be changed by adjusting primary voltage $U_{1}$ (e.g. by using thyristor regulators, by altering inductive impedance or resistance of stator windings and rotor circuit, by developing an additional braking torque on the engine shaft and by non-symmetrical voltage alteration of the stator winding's clamps);

4) by adjusting slip (using a part of slip energy), i.e. by introducing slip frequency electromotive force $E_{2}$, $f_{2}=s f_{1}$ into the rotor circuit (cascade speed control circuits of asynchronous motors);

5 ) by varying the number of pairs of poles and adjusting slip by thyristor voltage regulators or regulating inductors (mixed regulation).

In order to determine the most effective method of regulation, let us consider the relationship between the torque developed by asynchronous motors with squirrelcage rotors and their parameters expressed by the formula:

$$
M=\frac{p_{1} m_{1} U_{1}^{2} \frac{r_{1}}{s}}{2 \pi f_{1}\left(r_{2}^{\prime}+\frac{r_{1}}{s}\right)+\left(x_{1}+x_{2}^{\prime}\right)} ;
$$

where $p_{1}$ and $m_{1}$ are the numbers of pairs of the stator's poles and phases; $r_{1}$ and $x_{1}$ denote resistance and inductive impedance of stator; $r_{2}^{\prime}$ and $x_{2}^{\prime}$ denote resistance and inductive impedance of rotor reduced in accordance with the stator's parameters; $U_{1}$ is supply voltage of the stator windings. If the voltage drop in the static winding is disregarded, then, $\left|U_{1}\right| \approx\left|E_{1}\right|$ (here, $E_{1}$ is EMF of the stator phase).

Taking into account that relative slip $s$ is small when asynchronous motor operates in a normal mode (in the part of speed-torque characteristic up to the point B) as well as assuming that $s_{2}=0$ and ignoring the resistance of the stator circuit, i.e. assuming $s r_{1} / r_{2}^{\prime}=0$, the torque can be expressed as follows:

$$
M=\frac{C U_{1}^{2} s}{f_{1}},
$$

where $C=p_{1} m_{1} /\left(2 \pi r_{2}^{\prime}\right)$.

Since the load and, consequently, the torque of an operating traction engine vary to a great extent, the conditions of the most economic mode should be satisfied. Under the above conditions, the losses should be minimal, i.e.:

$$
\Delta P_{\min }=\left(\Delta P_{m}+\Delta P_{\text {mag }}+\Delta P_{2}\right)_{\min }=\text { const },
$$

where $\Delta P_{m}$ and $\Delta P_{m a g}$ are mechanical and magnetic losses of an engine, which, according to the above assumptions, do not depend on the engine load, i.e. the rotor current $I_{2} ; \Delta P_{2}=M\left(n_{1}-n_{2}\right)$ denote power losses in the rotor.

The difference between the rotational speed of the stator magnetic field $n_{1}=2 \pi f_{1} / p$ and of the rotor, $n_{2}=2 \pi f_{2} / p$, is referred to as absolute rotor slip and is equal to:

$$
\Delta n=n_{1}-n_{2}=\frac{2 \pi}{p} \Delta f .
$$
follows:

Then, power losses in the rotor circuit will be as

$$
\Delta P_{2}=\frac{2 \pi}{p} M\left(f_{1}-f_{2}\right)=\frac{2 \pi}{p} M \Delta f .
$$

Under the condition $\Delta P_{\min }=$ const , absolute rotor slip $\Delta f$ should be minimal and invariable in all modes of operation:

$$
\Delta f=\left(f_{1}-f_{2}\right)_{\min }=\text { const } .
$$

Let us consider two loading modes of asynchronous motor with squirrel-cage rotor to determine (9) how the above condition can be met. In the first case, the supply power of the stator is $U_{1}$ and its frequency $f_{1}$, while in the second case, these are $U_{1}^{\prime}$ and $f_{1}^{\prime}$, respectively. Relative slip of the rotor will be 
$s_{1}=\left(f_{1}-f_{2}\right) / f_{1}$ and $s_{1}^{\prime}=\left(f_{1}^{\prime}-f_{2}^{\prime}\right) / f_{2}^{\prime}$, respectively.

According to the formula (5), the developed torque of asynchronous motor operating in the first mode will be as follows:

$$
M_{1}=C \frac{U_{1}^{2}}{f_{1}} \quad \frac{f_{1}-f_{2}}{f_{1}}=C \frac{U_{1}^{2}\left(f_{1}-f_{2}\right)}{f_{1}^{2}},
$$

while for the second mode it will be:

$$
M_{1}^{\prime}=C \frac{\left(U_{1}^{\prime}\right)^{2}}{f_{1}^{\prime}} \quad \frac{f_{1}^{\prime}-f_{2}^{\prime}}{f_{1}^{\prime}}=C \frac{\left(U_{1}^{\prime}\right)^{2}\left(f_{1}^{\prime}-f_{2}^{\prime}\right)}{\left(f_{1}^{\prime}\right)^{2}} .
$$

Since the equality

$\left(f_{1}-f_{2}\right)_{\min }=\left(f_{1}^{\prime}-f_{2}^{\prime}\right)_{\min }=$ const should be satisfied according to the formula (10) to meet the condition of constant losses in asynchronous motor, then, according to (10) and (11), the relation between the torques in the modes considered will be described by the expression:

$$
\frac{M_{1}}{M_{1}^{\prime}}=\frac{C U_{1}^{2}\left(f_{1}-f_{2}\right)_{\min }}{f_{1}^{2}} \frac{\left(f_{1}^{\prime}\right)^{2}}{C\left(U_{1}^{\prime}\right)^{2}\left(f_{1}-f_{2}\right)_{\min }}=\frac{U_{1}^{2}}{\left(U_{1}^{\prime}\right)^{2}} \frac{\left(f_{1}^{\prime}\right)^{2}}{f_{1}^{2}} .
$$

It follows that:

$$
\frac{U_{1}}{U_{1}^{\prime}}=\frac{f_{1}}{f_{1}^{\prime}} \sqrt{\frac{M_{1}}{M_{1}^{\prime}}}
$$

Hence, an optimal mode of operation of asynchronous motors with squirrel-cage rotors is defined by the relationship between their three parameters amplitude of voltage $U_{1}$, frequency $f_{1}$ and the developed torque $M_{1}$. By varying the above relationship [according to (12)], the conditions of minimal losses and constant overload coefficient, while retaining high efficiency $\eta$, power-to-weight ratio $\cos \varphi$ and stability margin in the range of asynchronous motor regulation, can be met. In the case of high loads, voltage drop in the resistance of stator winding is taken into account. To achieve better performance, voltage regulation is corrected by taking into account actual voltage of the stator. For this purpose, automatic voltage control by microprocessors allowing for compensating voltage drop in the resistance stator winding should be provided.

A mode of operation of a locomotive can be described by the locomotive speed $V$ and traction force $F_{k}$ of wheel-set. It was found that: $v=0,188 \frac{D}{\mu} \frac{60 f_{1}}{p}(1-s)$ or: $v=0,188 \frac{D}{\mu} \frac{60 f_{1}}{p}=C_{1} f_{1}$ and: $F_{k}=\frac{2 M}{D} \mu \eta_{p}=C_{2} M$ in the part of speed-torque where $s$ is small (here, $D$ is the diameter of the locomotive wheel-set; $\mu$ is gear ratio of the gear drive; $\eta_{p}$ is gear drive efficiency).

On the basis of the formula (12), we can determine mode control of locomotives with asynchronous motors:

$$
\frac{U_{1}}{U_{1}^{\prime}}=\frac{v_{1}}{v_{1}^{\prime}} \sqrt{\frac{M_{1}}{M_{1}^{\prime}}} \text { or } \frac{U_{1}}{U_{1}^{\prime}}=\frac{v_{1}}{v_{1}^{\prime}} \sqrt{\frac{F_{k}}{F_{k}^{\prime}}} \text {. }
$$

In this case, speed $v_{1}$ and traction force $F_{1}$ correspond to frequency $f_{1}$ and supply voltage $U_{1}$ or $v_{1}^{\prime}$ and $F_{k,}^{\prime}$ - traction force in presence of frequency of voltage $U_{1}^{\prime}$.

Assuming that $P_{1} / P_{2}=F_{1} v_{1} / F_{k}^{\prime} v_{1}^{\prime}=1$ (where $P_{1}, P_{2}$ denote tractive power of wheelsets) and raising both sides of equation (13) to the square, we get:

$$
\frac{U_{1}^{2}}{\left(U_{1}^{\prime}\right)^{2}}=\frac{v_{1}^{2} F_{k}}{\left(v_{1}^{\prime}\right)^{2} F_{k}}
$$

It follows that:

$$
\frac{U_{1}}{U_{1}^{\prime}}=\sqrt{\frac{v_{1}}{v_{1}^{\prime}}}
$$

To maintain the engine power constant, the supply voltage should be varied proportionally with the square root taken of tractive force.

The mode of constant speed of the locomotive, when $v=$ const or $v_{1} / v_{1}^{\prime}=1$, meets the condition $f_{1} / f_{1}^{\prime}=1$. Besides, it follows from the formula (13) that $U_{1} / U_{1}^{\prime}=\sqrt{F_{k} / F_{k}{ }^{\prime}}$. This means that, in order to maintain the locomotive speed constant, the supply voltage should be varied proportionally with the square root taken of tractive force. If the voltage applied to the engine is maintained constant, i.e. $U_{1} / U_{1}^{\prime}=1$, then, by calculating (13), we will get $U_{1} / U_{2}^{\prime}=\sqrt{F_{k} / F_{k}{ }^{\prime}}=1$.

Accordingly, traction characteristic $F_{k}(V)$ varies in a manner predetermined by square hyperbola, which is similar to the characteristic of series excitation of non-saturated magnetic system of an engine. By varying the frequency of constant supply voltage in inverse proportionality to traction, we get a drooping engine 
characteristic, satisfying the condition of minimal losses, constant load factor, high efficiency $\eta$, power factor $\cos \varphi$ and stability margin in the range of regulation. For example, under the condition of constant supply voltage with the frequency $f=50 \mathrm{~Hz}$, the engine develops tractive force $F_{k}$ (Fig 3, line 1).

When the speed increases, the frequency of the supply voltage also increases. For example, if the speed increased by $\sqrt{2}$ times, i.e. $f_{1}^{\prime}=\sqrt{2} \cdot 50=70 \mathrm{~Hz}$, then, the tractive force would decrease by $\sqrt{F_{k} / F_{k}{ }^{\prime}}$ according to (14) and would be the half of the initial $F_{k}$ value, i.e. $F_{k}^{\prime}=0,5 F_{k}$.

As shown by the graphs (see Fig 3), absolute motor slip $\Delta f$ remains unchanged. If the locomotive speed has increased twice compared to the initial speed, i.e. $f_{1}^{\prime \prime}=2 f_{1}=100 \mathrm{~Hz}$, then, according to (13), we get $v_{1}^{\prime \prime} / v_{1}=f_{1}^{\prime \prime} / f_{1}=\sqrt{F_{k} / F_{k}{ }^{\prime \prime}}$ for the same supply voltage.

It follows that $F_{k}^{\prime \prime}=0,25 F_{k}$, i.e. when the speed is increased twice, the tractive force makes it reduced to one fourth of the original $F_{1}$ value, corresponding to $f_{1}=50 \mathrm{~Hz}$.

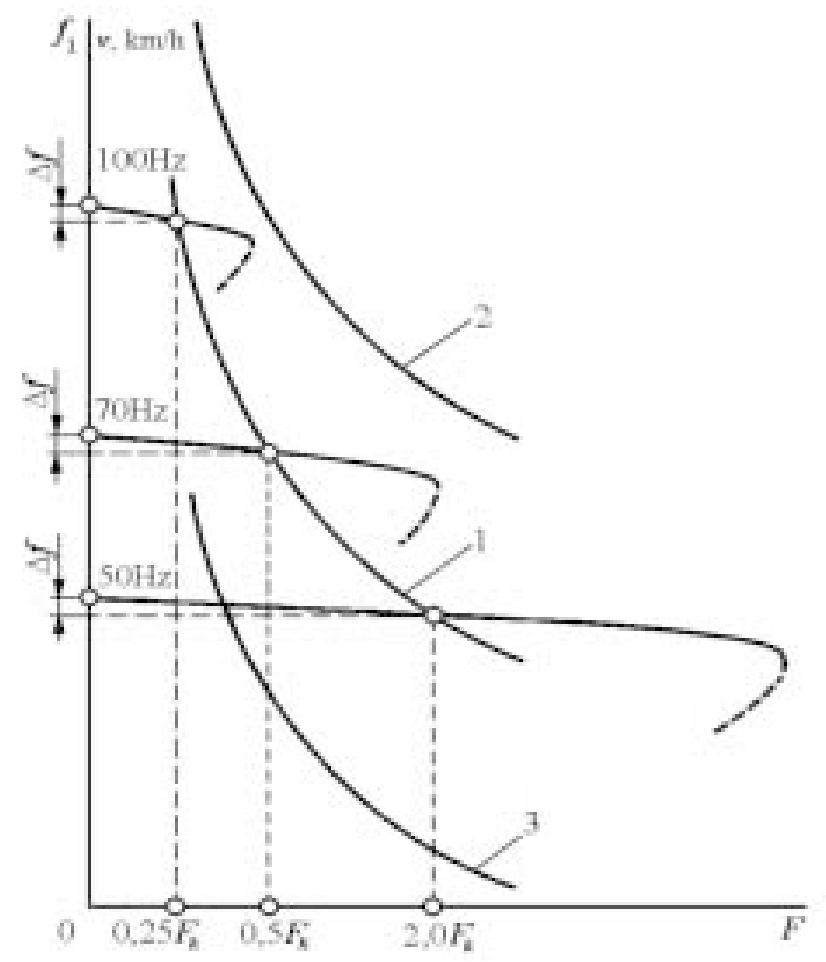

Fig 3. Characteristics of asynchronous traction motor with frequency controlled speed
Absolute slip of traction motors and the respective locomotive losses are minimal.

When the supply voltage is increased, the characteristics move to the area of higher speed (Fig 3, line 2). By changing simultaneously the supply voltage $U_{1}$ and its frequency $f_{1}$, depending on mode regulation, any flat characteristic can be obtained.

\section{Conclusions}

1. Mode regulation of asynchronous motors with cage rotors presented in the paper allows for efficient control of the speed of the rotor, as well as torque and traction in the speed range of the locomotive, maintaining constant load factor, minimal losses, high efficiency and power factor, and stability margin.

2. The regulation algorithm offered allows us to obtain various types of flat characteristics enabling asynchronous traction motor to be extensively used in traction, recuperation and dynamic braking modes of operation.

3. Varying speed-torque characteristics of asynchronous traction motors by using automatic regulation systems, it is possible to increase tractive power of the starting locomotive compared to DC traction motors.

4. Given the optimal methods of regulating the parameters of asynchronous thyratron traction motors, the electric machines of the described type can be recommended for the exclusive use in developing traction. Asynchronous traction motors with the socalled squirrel-cage rotors are simple in design and actually failure-free, thereby considerably prolonging the maintenance intervals.

5. Direct current traction motors are not reliable because of the commutator unit. Their disadvantages are associated with complicated commutation processes which, due to electromagnetic and mechanical effects, cause sparking at the commutator and brushes. Moreover, they are heavier and more expensive than $\mathrm{AC}$ traction motors, requiring higher maintenance expenses and having a short service life and low reliability.

6. The use of traction motors without commutators is particularly effective [8] in developing electric drives for powerful locomotives. The company VOITH TURBO has already achieved the power limit of $1500 \mathrm{~kW}$ for mechanical and hydrodynamic drives. The $\mathrm{AC}$ motor power of the locomotives is more than $7500 \mathrm{~kW}$.

7. Thyratron motor has not been extensively used for traction yet. However, powerful and high-speed motors can be developed in the future by using vector control [9] of the rotor angle. Theoretical aspects of this type of drives are not considered here, and only some 
design variants of the drives based on the use of thyratron traction motors are provided.

\section{References}

1. Baublys, A. Introduction to the theory of transport system (Transporto sistemos teorijos ivvadas). Vilnius: Technika, 1997. 298 p. (in Lithuanian).

2. Lingaitis, L. P. Maintenance and reliability of electric trains (Elektrinių riedmenų priežiūra ir patikimumas). Vilnius: Technika, 2001. 232 p. (in Lithuanian).

3. Strekopytov, V. V.; Grishchenko, A. B.; Kruchek, V. A. Electric drives of the locomotives (Электрические передачи локомотивов). Moscow: Marshrut, 2003. 305 p. (in Russian).

4. Crowder, R. M. Electric Drives and Their Controls. Oxford: Oxford University Press, 1998. 256 p.

5. Subrahmanyan, V. Electric Drives. USA: McGraw-Hill, 1976. $715 \mathrm{p}$.

6. Masiokas, S. Electrical engineering (Elektrotechnika). Kaunas: Candela, 1994. 431 p. (in Lithuanian).

7. Geleževičius, V.; Kriščiūnas, K.; Kubilius, V. Control systems of electric drives (Elektros pavarų valdymo sistemos). Vilnius: Mokslas, 1990.358 p. (in Lithuanian).

8. Vaičiūnas, G.; Lingaitis, L. P.; Bureika, G. The determination of a complex criterion for assessing the performance of traction rolling stocks. Transport, Vol XIX, No 2, 2004, p. 63-68.

9. Kuś, W. Vector control in AC motors. Elektronika Praktyczna, 9/200, p. 51-56. 